\title{
Donor Quality Scoring Systems and Early Renal Function Measurements in Kidney Transplantation
}

\author{
Quirino Lai et al.* \\ Department of General surgery and Organ transplantation, \\ Sapienza University of Rome, Rome \\ Italy
}

\section{Introduction}

Over the last years, an extensive improvement in the use of non-standard kidney allografts from deceased donors has been observed due to a chronic scarcity in the number of available donors. However, use of these donors seems to give worse results, higher delayed graft function (DGF) and rejection rates and briefer graft survivals.

Nevertheless, a standardized definition of non-standard donor is still under debate.

On these grounds, several studies have focalized on the importance of events immediately before or early post-transplant in determining allograft outcome: introduction of scores based on peri-operative features capable to predict graft function may yield huge implications for organ allocation policies, as well as for immediate and late clinical and immunological management of recipients. In fact, if pre-KT information could accurately predict suboptimal early graft function, the success of various mechanical, immunosuppressive and organ allocation strategies may be improved.

The aim of this review is to analyze the different pre- and post-transplant score systems, detecting their role in the clinical practice and comparing them in terms of prognostic ability.

\section{Donor quality scoring systems}

In the last decades, several different scoring systems based on donor, recipient and transplant parameters have been proposed with the intent to predict early and late post-KT graft function.

Despite several of these scores have been validated on large cohorts or have been adopted by national allocation systems, no one of them has been already internationally recognized as the best model for graft function prediction.

We analyzed these scores, stratifying them in three groups according to the different parameters by which they are composed: demographic and serological variables, histological graft variables, donor and histological graft variables.

*Francesco Nudo, Vincenzo Morabito, Giovanni Battista Levi Sandri, Fabio Melandro, Lucia Parlati, Nicola Guglielmo, Marco Di Laudo, Manuela Garofalo, Luca Poli, Renzo Pretagostini and Pasquale B Berloco 


\subsection{Demographic and serological variables}

Several scores exclusively based on donor features or composed by a combination of parameters obtained by donor, transplant and donor-recipient match have been created. Some of these scores are commonly adopted in the care practice: we reported the most commonly used.

\subsubsection{ECD}

In March 2001, a consensus meeting who took place in Crystal City introduced a new definition of expanded criteria donor (ECD) (Rosengard et al, 2002). Under the work group's proposed plan, the Organ Procurement and Transplantation Network (OPTN), through its contract with the United Network for Organ Sharing (UNOS) developed a standard policy for national kidney allocation in the United States. In November 2001, the OPTN/UNOS Board of Directors adopted the new ECD definition and the new allocation system became operative in October 2002. The new definition of ECD derived from four different donor risk factors for graft failure: age, history of hypertension, cerebrovascular accident as a cause of death and final pre-procurement creatinine $>1.5 \mathrm{mg} / \mathrm{dL}$.

Different combinations of these four parameters characterized each donor kidney and a relative risk of graft loss was determined for each donor profile (Figure 1).

\begin{tabular}{|c|c|c|c|c|}
\hline \multirow{3}{*}{$\begin{array}{l}\text { Age } \\
\text { (years) }\end{array}$} & \multicolumn{4}{|l|}{$\mathrm{RR}$} \\
\hline & \multicolumn{2}{|c|}{ Normal creatinine } & \multicolumn{2}{|c|}{ High creatinine } \\
\hline & No HTN & HTN & No HTN & HTN \\
\hline \multicolumn{5}{|c|}{ Cause of death was not cerebrovascular accident } \\
\hline $0-9$ & $1.40^{* *}$ & $1.59^{* *}$ & $1.52^{* *}$ & - \\
\hline $10-39$ & 1.00 & $1.14^{* *}$ & $1.09^{*}$ & $1.24^{* *}$ \\
\hline $40-49$ & $1.17^{* *}$ & $1.33^{* *}$ & $1.28^{* *}$ & $1.45^{* *}$ \\
\hline $50-59$ & $1.41^{* *}$ & $1.60^{* *}$ & $1.53^{* *}$ & $1.74^{* *}$ \\
\hline $60+$ & $1.90^{* *}$ & $2.16^{* *}$ & $2.07^{* *}$ & $2.36^{* *}$ \\
\hline \multicolumn{5}{|c|}{ Cause of death was cerebrovascular accident } \\
\hline $0-9$ & $1.60^{* *}$ & $1.82^{* *}$ & $1.74^{* *}$ & $1.98^{* *}$ \\
\hline $10-39$ & $1.14^{* *}$ & $1.30^{* *}$ & $1.24^{* *}$ & $1.41^{* *}$ \\
\hline $40-49$ & $1.34^{* *}$ & $1.52^{* *}$ & $1.46^{* *}$ & $1.66^{* *}$ \\
\hline $50-59$ & $1.61^{* *}$ & $1.83^{* *}$ & $1.75^{* *}$ & $1.99^{* *}$ \\
\hline $60+$ & $2.17^{* *}$ & $2.47^{* *}$ & $2.37^{* *}$ & $2.69^{* *}$ \\
\hline
\end{tabular}

Fig. 1. Relative risks (RR) of graft loss by four donor characteristics. Taken from Metzger et al., 2003.

The ECD kidney was then arbitrarily defined as any kidney whose relative risk of graft failure exceeded 1.7 when compared to a reference group of ideal donor kidneys (age 10-39 years, no hypertension, no cerebrovascular accident as cause of death and terminal predonation creatinine level $<1.5 \mathrm{mg} / \mathrm{dL}$ ). 
The definition of ECD status is the following (Table 1):

a. Donor age older than 59 years;

b. Donor age between 50 and 59 years with, additionally two of the following: death caused by cerebrovascular accident (CVA); terminal creatinine more than $1.5 \mathrm{mg} / \mathrm{dL}$; history of hypertension.

\begin{tabular}{|c|c|c|c|c|c|}
\hline \multirow[b]{2}{*}{ Donor condition } & \multicolumn{5}{|c|}{ Donor age categories (years) } \\
\hline & $<10$ & $10-39$ & $40-49$ & $50-59$ & $\geq 60$ \\
\hline $\mathrm{CVA}+\mathrm{HTN}+$ Creat $>1.5$ & & & & $X$ & $X$ \\
\hline $\mathrm{CVA}+\mathrm{HTN}$ & & & & $X$ & 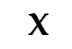 \\
\hline CVA + Creat $>1.5$ & & & & $x$ & $X$ \\
\hline HTN + Creat $>1.5$ & & & & $X$ & $\mathbf{X}$ \\
\hline CVA & & & & & $\mathrm{X}$ \\
\hline HTN & & & & & $X$ \\
\hline Creat $>1.5$ & & & & & $X$ \\
\hline None of the above & & & & & $X$ \\
\hline
\end{tabular}

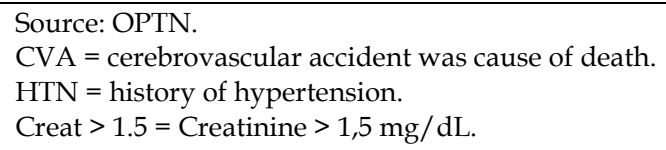

Table 1. ECD for kidney donors. Taken from Rosengard et al., 2002 (with modifications).

A multicentre study (Metzger et al., 2003) based on OPTN/SRTR data showed a progressive increase in ECD utilization across the years, confirming the worse results obtained from these donors in terms of both patient and graft survivals.

Nevertheless, a more rational definition of ECD has given major opportunities to patients who had presented limited access to KT to be transplanted.

A monocentre analysis (Stratta et al., 2004) reported an effective increased volume of KTs within 1 year after the adoption of ECD policy; moreover, the authors observed similar results in terms of graft function and morbidity among recipients who received organs from standard or ECD. A systematic approach to ECD kidneys based on nephron mass matching and nephron sparing measures showed to provide optimal short-term outcomes and renal function comparable to standard kidneys.

\subsubsection{DDS}

Using ECD, a better allocation policy was obtained. On the other hand, the binary nature of the ECD definition may have underappreciated the variability of the quality of the organ.

On these grounds, (Nyberg et al., 2001) a more granulated scoring system (deceased donor score, DDS) was developed. DDS was based on seven different donor variables easily available at the moment of procurement. The end measure for the development of the score was the 6-month creatinine clearance value.

The variables analyzed were:

Cause of death (0-6 points), history of hypertension (0-6), renal creatinine clearance before procurement (0-6), age (0-6), history of diabetes mellitus (0-3), cold ischemia time (0-3) and severity of renal artery plaque (0-3). 
The population enrolled for the study (241 cadaveric KT recipients) was stratified in four groups: grade A (0-5 points), grade B (6-10), grade C (11-15) and grade D (16-32).

Adoption of this score permitted an effective stratification of the population, showing that information available at the time of organ harvesting may estimate early graft function after cadaveric renal transplantation.

The same Authors (Nyberg et al., 2003) improved on their original scoring system studying the data $34.324 \mathrm{KT}$ patients reported in the OPTN/SRTR registry. The five donor variables adopted were:

Age (0-25 points), history of hypertension (0-4), creatinine clearance before procurement (0-4), cause of death (0-3), HLA mismatch (0-3).

The entire population was stratified in four different grades according to the cumulative donor score: grade A (0-9 points), grade B (10-19), grade C (20-29) and grade D (30-39).

The influence of donor score on both graft function and survival was most severe above 20 points (Figure 2).

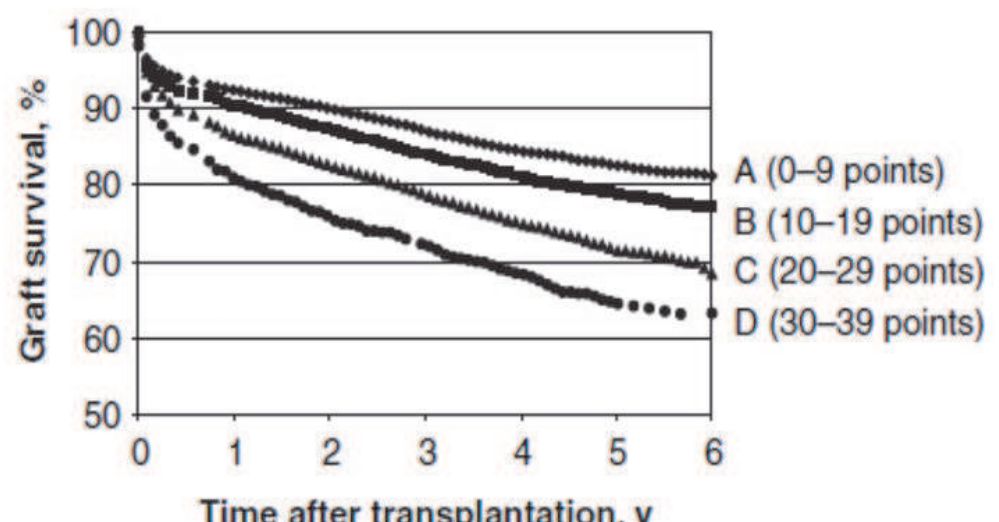

Fig. 2. Nyberg score grading significantly influences graft survival after transplantation. The greatest 6-year graft survival difference was observed between grades B and C, suggesting a cutoff for 'marginal' kidneys of approximately 20 points. Taken from Nyberg et al., 2003.

Afterwards, according to Nyberg score, this threshold value designates "marginal" kidneys.

\subsubsection{DGF nomogram}

According to the most commonly adopted definition, DGF is the need for dialysis in the first week after transplantation.

A multicentre study (Irish et al., 2003) analyzed data obtained from 13.846 patients reported in the United States Renal Data System (USRDS) registry from 1995 to 1998. Using a multivariable logistic regression analysis, factors contributing to DGF were analyzed.

The pre-KT donor and recipient factors analyzed were:

Donor: age, history of hypertension, terminal creatinine, donation after cardiac death, death caused by anoxia or CVA; cold ischemia time; HLA mismatch; combined organ transplantation.

Recipient: gender, race, diabetes, history of previous transplantation, history of transfusion, history of dialysis before transplantation, peak panel reactive anti-HLA antibodies. 
A nomogram quantifying the relative contribution of each risk factor was created, providing a useful tool for developing a pretransplantation index of the likelihood of DGF occurrence (Figure 3).

Seven years later, a new analysis (Irish et al., 2010) was performed on 24.337 patients transplanted during the period 2003-2006. The authors developed a novel nomogram and a web-based calculator (http://www.transplantcalculator.com/DGF) as an easily accessible tool for predicting DGF.

Comparing risk factors in the modern (2003-2006) and in the earlier era (1995-1998), weight of immunological factors attenuated, while impact of donor renal function increased by 2fold. The most significant factors associated with DGF were cold ischemia time, donor creatinine, body mass index, donation after cardiac death and donor age.

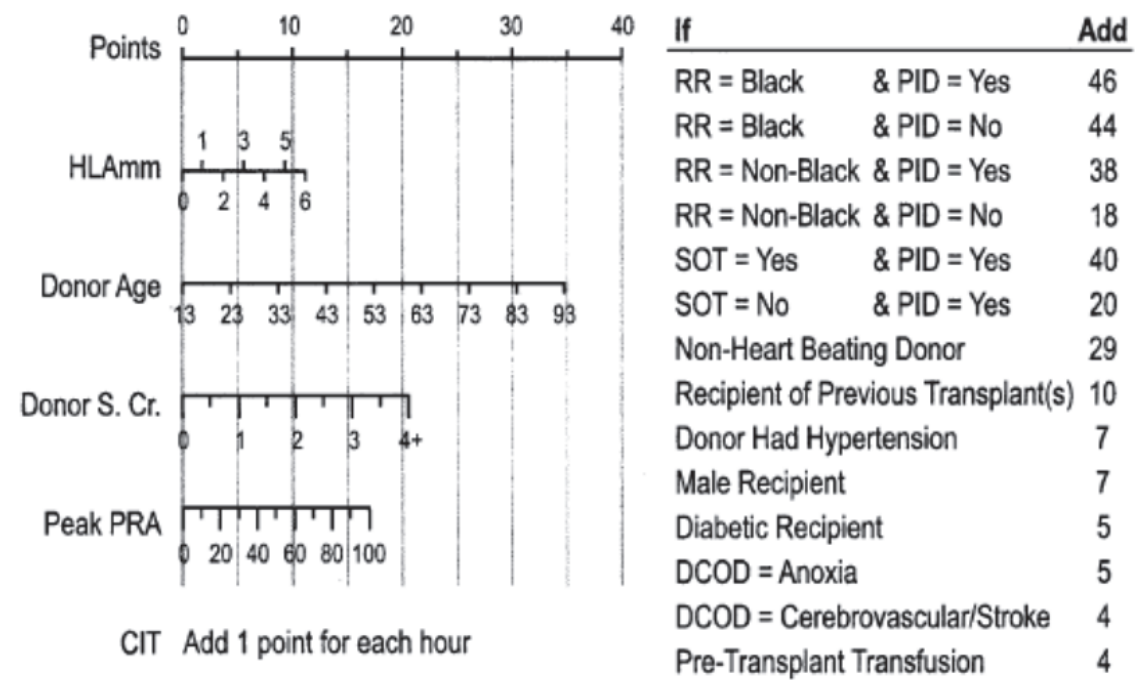

Total Points

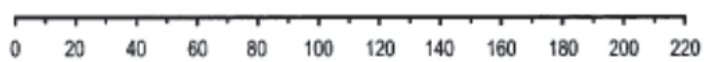

Risk of DGF

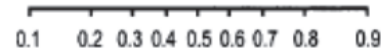

Abbreviations: $D C O D=$ Donor Cause of Death $\quad P I D=$ Pre-Transplant Dialysis

$R R=$ Reciplent Race $\quad S O T=$ Single Organ Transplant

Fig. 3. Nomogram for estimating the risk of delayed graft function (DGF) in adult renal transplant recipients. HLAmm, HLA mismatch; S.Cr., serum creatinine; PRA, panel-reactive antibody; CIT, cold ischemia time; RR, recipient race; PID, pre-transplantation dialysis; DCOD, donor cause of death; SOT, single-organ transplant. Taken from Irish et al., 2003. 


\subsubsection{Pessione score}

A retrospective analysis of a cohort of 7.209 deceased KT recipients transplanted in France from 1996 to 2000 was performed and a new scoring system (Pessione et al.. 2003) was ideated.

After multivariate analysis, only three parameters resulted as significant independent risk factors for graft failure:

Cerebrovascular cause of death, history of hypertension and elevated serum creatinine $(>150$ micromol/L).

Donor age $>60$ years was a statistically significant, but dependent, risk factor. The increased risk of graft loss in patients who presented the cumulative effect of donor risk factors was greater in recipients aged more than 60 years (one risk factor: $R R=1.8$; two risk factors: $R R$ $=2.7$ ) (Figure 4).

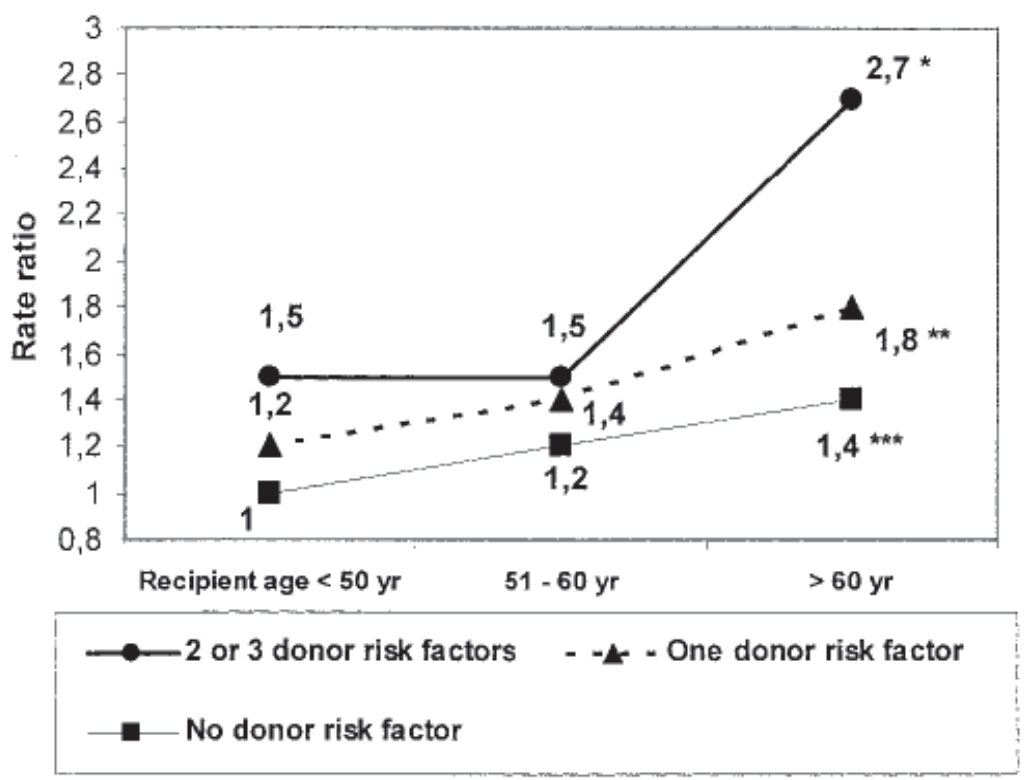

Fig. 4. Rate ratios of graft failure according to the absence or the presence of one or $>2$ significant donor risk factors in the different recipient age groups. ${ }^{*} p$-value $=0.008$ (vs. patients $<60 \mathrm{yr}$ ), ${ }^{* *}$ p-value $=0.04$ (vs. patients $<60 \mathrm{yr}$ ), ${ }^{* * *}$ p-value $=\mathrm{NS}$ (vs. patients $<60 \mathrm{yr}$ ). Taken from Pessione et al., 2003.

\subsubsection{DRS}

Donor risk score (DRS) (Schold et al., 2005) represents a model in which not only significant donor features, but also donor-recipient matches and cold ischemia time are adopted.

The variables used for the creation of the score were:

Donor race; donor history of hypertension; donor history of diabetes; donor death due to CVA; cold ischemia time; HLA mismatch; donor/ recipient cytomegalovirus (CMV) match.

The following grades based on accumulated "points" have been proposed: grade I (0-0.234), grade II (0.234-0.524), grade III (0.524-0.853), grade IV (0.853-1.17), and grade V (>1.17). 
Adopting this model, the projected half-lives by donor grade, calculated utilizing data beyond 2-year posttransplant, were: grade I = 10.7 years; II = 10.0 years; III = 7.9 years; IV = 5.7 years; $\mathrm{V}=4.5$ years.

Comparing DRS with ECD and Nyberg score, the first one was the best model in graft loss stratification (Figure 5).

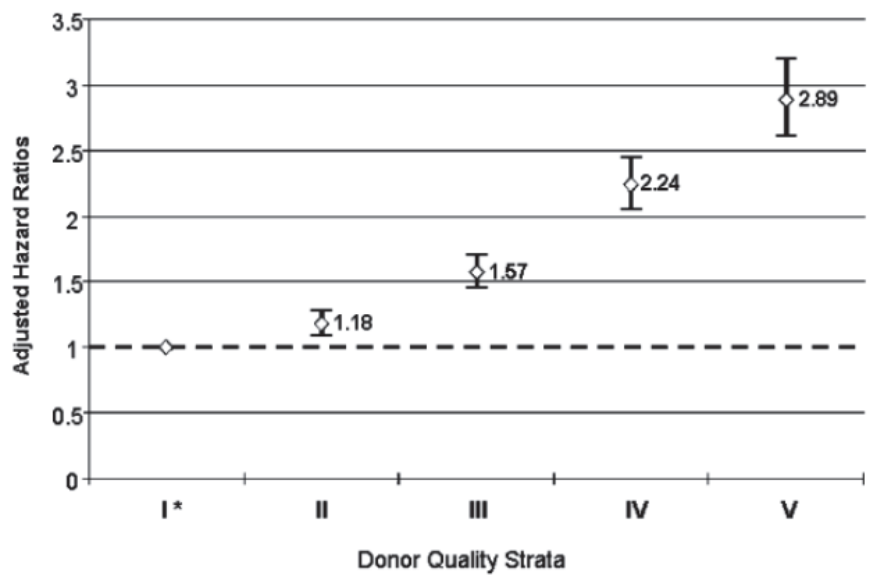

Fig. 5. Multivariate estimates for graft loss by donor grade. *Grade I donor serves as the reference group in the model. Taken from Schold et al., 2005.

\subsubsection{KDRI}

Kidney donor risk index (KDRI) (Rao et al., 2009) was proposed as a continuous combining donor and transplant variables to quantify graft failure risk. The authors analyzed 69.440 patients using national data from 1995 to 2005.

The fourteen proposed KDRI donor and transplant factors, each found to be independently associated with graft failure or death, were:

Donor: age, race, history of hypertension, history of diabetes, serum creatinine, cerebrovascular cause of death, height, weight, donation after cardiac death, hepatitis $C$ virus status;

Transplant: human leukocyte antigen-B and DR mismatch, cold ischemia time, double or en bloc transplant.

The KDRI reflected the rate of graft failure relative to that of a healthy 40 -year-old donor. Transplants of kidneys in the highest KDRI quintile $(>1.45)$ had an adjusted 5-year graft survival of $63 \%$, compared with $82 \%$ and $79 \%$ in the two lowest KDRI quintiles $(<0.79$ and $0.79-<0.96$, respectively) (Figure 6).

\subsubsection{DGF score}

An analysis on a monocentre cohort of Italian KTs (Pretagostini et al., 2009) was performed with the intent to define the risk factors for the development of DGF.

The authors found five different donor and transplant parameters most commonly observed in non standard donors:

Donor age $\geq 60$ years $(P=0.005)$, Creatinine Clearance $<40 \mathrm{~mL} / \mathrm{min}(P=0.025)$, history of diabetes mellitus $(P=0.026)$, history of hypertension $(P=0.017)$, and cold ischemia time $>15$ hours $(P<$ 0.0001). 


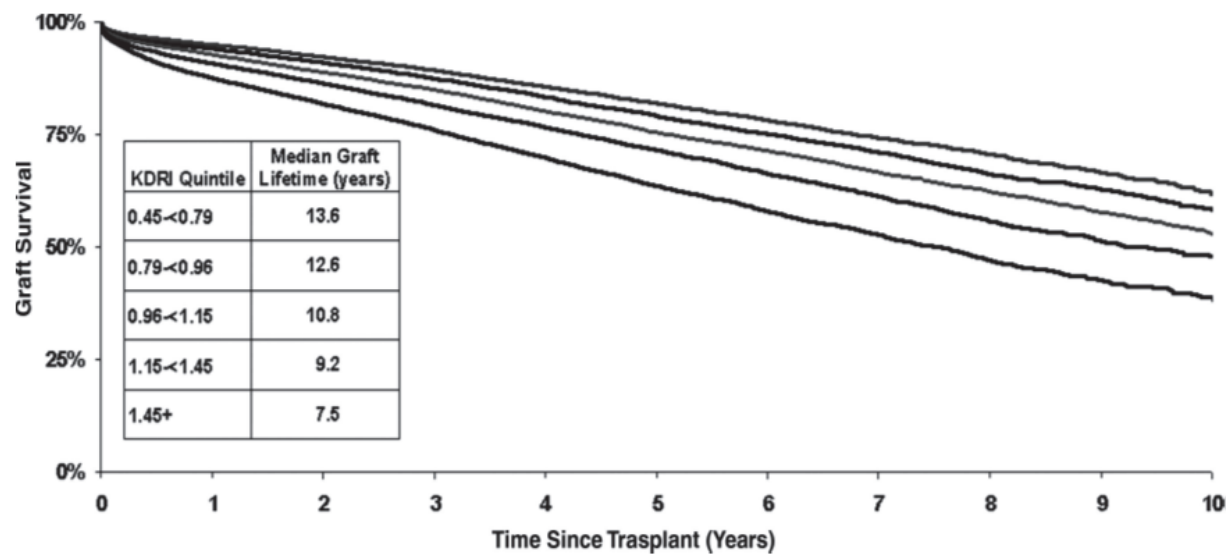

Fig. 6. Adjusted graft survival by KDRI quintile. Each survival pertains to a recipient who is aged 50 years, non-diabetic, and at the reference level of all other recipient factors. Extrapolation was used for the first and second quintile. Taken from Rao et al., 2009.

\subsection{Histological graft variable}

Above clinical features, another adopted approach fo4r the identification of high-risk kidneys is to use a pre-KT biopsy in order to characterize potential kidney grafts, help predict the graft outcome and provide a reference point for analysis of subsequent biopsies. Several different histological parameters have been correlated with poor outcomes (i.e. percentage of sclerotic glomerules, degree of tubulointerstitial and chronic vascular lesions). Starting from these considerations, all these histological changes were integrated into histological scoring systems with the intent to consent a better allocation of kidneys from elder donors. All the histological scores reported in literature in the last decades were based on the previously proposed semiquantitative analysis of renal histology (Pirani \& SalinasMadrigal, 1975).

\subsubsection{Remuzzi score}

The results of a consensus created by an international panel of pathologists (Remuzzi et al., 1999) consented the creation of a new score, This method was presented for the evaluation of kidneys procured from donors older than 60 years of age. This new method quantified the number of nephrons for each kidney with the intent to estimate if the grafts should be available for KT and whether single or dual transplantation should be used. This panel suggested a biopsy-based score ranging from a minimum of 0 (indicating the absence of renal lesions) to a maximum of 12 (indicating the presence of marked changes in the renal parenchyma) (Table 2).

The four different parameters considered in the scoring system were:

Glomerular global sclerosis (0-3), tubular atrophy (0-3), interstitial fibrosis (0-3) and arterial and arteriolar narrowing (0-3).

Kidneys with a score of 3 or lower were predicted to contain enough viable nephrons to be used as single transplants. Those with a score of 4,5 , or 6 could be used as dual transplants, on the assumption that the sum of the viable nephrons in the two kidneys approached the number in one ideal kidney. Kidneys with a score of 7 or greater were discarded, since it 
was assumed that they would deliver an insufficient dose of nephrons, even in a dual transplantation.

The validity of the score was tested (Remuzzi et al., 2006) analyzing a prospective cohort study of 62 patients who received one or two histologically evaluated kidneys from donors older than 60 years of age.

The outcomes of these grafts were compared with the outcomes among 248 matched recipients of single kidney grafts that had not been histologically evaluated and were either from 124 donors with age $\leq 60$ years or from 124 donors older than 60 years.

\begin{tabular}{|c|}
\hline ive method of \\
\hline $\begin{array}{l}\text { Glomerular global sclerosis } \\
\text { Based on three sections (the first, middle, and last sections, if available); the number of } \\
\text { globally sclerosed glomerules expressed as a percentage. } \\
0 \text { none globally sclerosed } \\
\begin{array}{l}1+<20 \% \text { global glomerulosclerosis } \\
2+20 \text { to } 50 \% \text { global glomerulosclerosis } \\
3+>50 \% \text { global glomerulosclerosis }\end{array}\end{array}$ \\
\hline $\begin{array}{l}\text { Tubular atrophy } \\
\begin{array}{l}0 \text { absent } \\
1+<20 \% \text { of tubuli affected } \\
2+20 \text { to } 50 \% \text { of tubuli affected } \\
3+>50 \% \text { of tubuli affected }\end{array}\end{array}$ \\
\hline $\begin{array}{l}\text { Interstitial fibrosis } \\
\begin{array}{l}0 \text { absent } \\
1+<20 \% \text { of renal tissue replaced by fibrous connective tissue } \\
2+20 \text { to } 50 \% \text { of renal tissue replaced by fibrous connective tissue } \\
3+>50 \% \text { of renal tissue replaced by fibrous connective tissue }\end{array}\end{array}$ \\
\hline $\begin{array}{l}\text { Arterial and arteriolar narrowing } \\
\text { For the vascular lesions, if the changes are focal, the most severe lesion present gives the } \\
\text { final grade. } \\
0 \text { absent } \\
1+\text { increased wall thickness but to a degree that is less than the diameter of the lumen } \\
2+\text { wall thickness that is equal or slightly greater to the diameter of the lumen } \\
3+\text { wall thickness that far exceeds the diameter of the lumen with extreme luminal } \\
\text { narrowing or occlusion }\end{array}$ \\
\hline $\begin{array}{lll}\text { Final grade (range from } 0 \text { to a total of } 12) & \\
\begin{array}{lll}0 \text { to } 3 & \text { mild } & \text { OK for single transplant } \\
4 \text { to } 6 & \text { moderate } & \text { OK for double transplant } \\
7 \text { to } 12 & \text { severe } & \text { should not be transplanted }\end{array} \\
\end{array}$ \\
\hline $\begin{array}{l}\text { \# Only biopsies with } \geq 25 \text { glomerules considered for slide evaluation. Kidneys with evidence of acute } \\
\text { tubular necrosis are not considered for the double transplant. Biopsies are graded as mild if they have } \\
0 \text { to } 3 \text { points in total provided they are less than } 3 \text { in any one category. Biopsies are graded as } \\
\text { moderate if they have } 4 \text { to } 6 \text { points in total provided they do not have } 3 \text { points in more than one } \\
\text { category. }\end{array}$ \\
\hline
\end{tabular}

Table 2. Histological score proposed by Remuzzi et al., 1999 (with modifications). 
Analyzing long-term graft survival, excellent results were observed using the grafts previously selected by biopsy.

Graft survival in recipients of histologically evaluated kidneys did not differ significantly from that of grafts from younger donors previously evaluated with biopsy. On the other side, survivals were strongly superior to that of elder grafts not pre-operatively evaluated with biopsy.

Adopting this score, long-term survival of single or dual kidney grafts from donors older than 60 years of age were similarly excellent, showing that systematic hystological approach may help to expand the donor-organ pool for kidney transplantation without a contemporaneous lack of results .

\subsubsection{Karpinski score}

A New study based on histological aspects (Karpinski et al., 1999) was performed on 57 allografts procured by 34 elderly donors (age $\geq 60$ years) with hypertension and/or vascular disease.

Graft survival of these patients was compared with the results of 57 control recipients selected to have similar baseline demographics but receiving transplants from younger donors.

Donor renal pathology was scored 0-3 (none to severe disease) in four areas (Table 3):

Glomerulosclerosis, tubular atrophy, interstitial fibrosis and vascular disease.

Vascular disease was composed by two different parameters (e.g. arteriolar narrowing and arterial sclerosis).

The number of sclerotic glomerules was expressed as a percent of the total number of glomerules available for evaluation.

For the vascular lesions, both arteries were evaluated separately. However, for the final vascular score, the most severe lesion of either arterioles or arteries determined the final grade. Each of the 4 compartments was given a score from 0 to 3 ; the total score was expressed out of 12 .

A donor vessel score of $3 / 3$ was associated with a $100 \%$ incidence of delayed graft function and poor 1-year graft function.

\subsection{Donor and histological graft variables}

A new model (Anglicheau et al., 2008) in which both histological and clinical variables were combined was developed in France. Before this study, in fact, a definitive role of preimplantation biopsies versus clinical scores had not been extensively studied in marginal donors.

Pre-KT biopsies of 313 grafts from donors aged more than 50 years were analyzed.

Authors evaluated the ability in predicting 1-year poor graft function (estimated glomerular filtration rate [eGFR] $<25 \mathrm{~mL} / \mathrm{min} / 1.73 \mathrm{~m} 2$ ) of several donor clinical and histological features.

In multivariate analysis, the clinical and histological features that resulted statistically significant were:

Clinical parameters $=$ donor hypertension and a serum Creatinine level $\geq 150 \mathrm{lmol} / \mathrm{L}$ before organ recovery.

Histological parameters: glomerulosclerosis, arteriolar hyalinosis, Pirani and CADI score.

However, the model who presented the highest performance in predicting low eGFR was achieved using a composite score that included donor serum creatinine $(\geq 150 \mathrm{lmol} / \mathrm{L}$ or $<150 \mathrm{lmol} / \mathrm{L}$ ), donor hypertension and glomerulosclerosis ( $\geq 10 \%$ or $<10 \%$ ) (Figure 7). 


\begin{tabular}{|l|}
\hline Pretransplant biopsy protocol: semiquantitative method of evaluation of slides \# \\
\hline Glomerular wcore \\
0 none globally sclerosed \\
$1+<20 \%$ global glomerulosclerosis \\
$2+20$ to $50 \%$ global glomerulosclerosis \\
$3+>50 \%$ global glomerulosclerosis \\
\hline Tubular score \\
0 absent \\
$1+<20 \%$ of tubuli affected \\
$2+20$ to $50 \%$ of tubuli affected \\
$3+>50 \%$ of tubuli affected \\
\hline Interstitial score \\
0 absent \\
$1+<20 \%$ of cortical parenchyma replaced by fibrous connective tissue \\
$2+20$ to $50 \%$ of cortical parenchyma replaced by fibrous connective tissue \\
$3+>50 \%$ of cortical parenchyma replaced by fibrous connective tissue \\
\hline Vascular score \\
Arteriolar narrowing (or hyaline arteriolosclerosis)\#\# \\
0 absent \\
$1+$ increased wall thickness but to a degree that is less than the diameter of the lumen \\
$2+$ wall thickness that is equal or slightly greater to the diameter of the lumen \\
$3+$ wall thickness that far exceeds the diameter of the lumen with extreme luminal \\
narrowing or occlusion \\
Arterial sclerosis (or intimal fibrous thickening-fibroplasia)\#\# \\
0 absent \\
$1+$ increased wall thickness but to a degree that is less than the diameter of the lumen \\
$2+$ wall thickness that is equal or slightly greater to the diameter of the lumen \\
$3+$ wall thickness that far exceeds the diameter of the lumen with extreme luminal \\
narrowing or occlusion \\
\hline \# Only biopsies with at least 20 glomerules are considered for slide evaluation. \#\# For the vascular \\
lesions, both arteries are evaluated separately. However, for the final vascular score, the most severe \\
lesion of either arterioles or arterie determines the final grade.
\end{tabular}

Table 3. Scoring system proposed by Karpinski et al., 1999 (with modifications). 


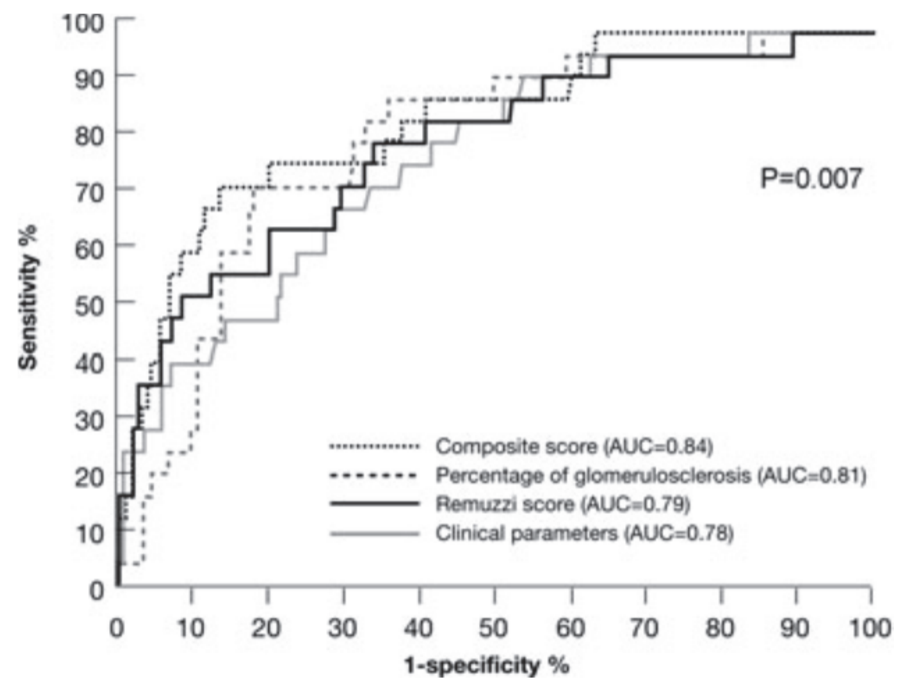

Fig. 7. Receiver operating characteristics (ROC) curves for clinical, histopathological and composite scoring systems as predictors of low eGFR at 1-year posttransplant. Global test: pvalue $=0.007$; composite score vs glomerulosclerosis: $\mathrm{p}$-value $=\mathrm{NS}$; composite score vs Pirani score: $p$-value $=0.001$; composite score vs clinical parameters: $p$-value $=0.009$ ). Taken from Anglicheau et al., 2008.

\section{Measures of early graft function}

Many measures of early graft function have been reported in Literature. Many of them were proposed with the intent to give a better definition of DGF. In fact, DGF is both an outcome and a predictor of the subsequent course of a renal transplant. Commonly adopted definition of DGF is the requirement for dialysis within the first week after KT (Daly et al., 2005). However, postoperative requirement of dialysis represents a very subjective and not standardized clinical decision. Recently, efforts have been made to quantify DGF more scientifically, adopting different scores based on urine output, serum creatinine levels, fluid overload and uremic status of the patient.

A comprehensive review of the literature (Yarlagadda et al., 2008) reported 18 different definitions for DGF (Table 4).

\begin{tabular}{|l|c|c|}
\hline \multicolumn{1}{|c|}{ Definitions } & $\begin{array}{c}\text { No. of } \\
\text { studies }\end{array}$ & $\begin{array}{c}\text { No. of } \\
\text { patients }\end{array}$ \\
\hline Dialysis-based definitions & 41 & 259.251 \\
\hline Need for dialysis in the first week after transplant & 2 & 760 \\
\hline $\begin{array}{l}\text { Need for dialysis in the first week after transplant once hyperacute } \\
\text { rejection, vascular and urinary tract complications were ruled out }\end{array}$ & 2 & 737 \\
\hline Need for dialysis after transplant & 1 & 41 \\
\hline Need for dialysis in the first 10 days after transplant & 1 & 547 \\
\hline $\begin{array}{l}\text { Absence of life-sustaining renal function that requires dialysis on two } \\
\text { or more occasions within the first week after transplant }\end{array}$ & & \\
\hline
\end{tabular}




\begin{tabular}{|c|c|c|}
\hline Definitions & $\begin{array}{l}\text { No. of } \\
\text { studies }\end{array}$ & $\begin{array}{c}\text { No. of } \\
\text { patients }\end{array}$ \\
\hline $\begin{array}{l}\text { Need for dialysis in the first } 7 \text { days after transplant with specific } \\
\text { exclusion of single early post-operative dialysis performed for } \\
\text { hyperkalemia }\end{array}$ & 1 & 319 \\
\hline $\begin{array}{l}\text { Return to maintenance hemodialysis within the first } 4 \text { days after } \\
\text { transplantation }\end{array}$ & 1 & 263 \\
\hline \multicolumn{3}{|l|}{ Creatinine-based definitions } \\
\hline $\begin{array}{l}\text { Serum creatinine increased or remained unchanged or decreased } \\
<10 \% / \text { day during } 3 \text { consecutive days after the transplant }\end{array}$ & 5 & 1471 \\
\hline $\begin{array}{l}\text { Creatinine reduction ratio }<30 \% \text { and / or urine creatinine on Day } 2 \\
<1000 \mathrm{mg}\end{array}$ & 2 & 401 \\
\hline $\begin{array}{l}\text { Serum creatinine }>2.5 \mathrm{mg} / \mathrm{dL} \text { on Day } 7 \text { or the need for post-transplant } \\
\text { hemodialysis }\end{array}$ & 1 & 99 \\
\hline $\begin{array}{l}\text { Time required for the kidney to reach } \mathrm{Crcl}>10 \mathrm{~mL} / \mathrm{min} \text { greater than } 1 \\
\text { week. }\end{array}$ & 1 & 843 \\
\hline $\begin{array}{l}\text { Failure of creatinine to decline in the first } 48 \mathrm{~h} \text { in the absence of } \\
\text { rejection }\end{array}$ & 1 & 291 \\
\hline \multicolumn{3}{|l|}{ Combination } \\
\hline $\begin{array}{l}\text { Failure of serum creatinine to fall below pre-transplant levels, within } 1 \\
\text { week regardless of the urine output }\end{array}$ & 1 & 158 \\
\hline $\begin{array}{l}\text { Patients with rise in serum } \mathrm{Cr} \text { at } 6-8 \mathrm{~h} \text { post-operatively or }<300 \mathrm{cc} \text { of } \\
\text { urine despite adequate volume and diuretics }\end{array}$ & 1 & 143 \\
\hline $\begin{array}{l}\text { Dialysis requirement after transplant or a serum creatinine } 150 \\
\mu \mathrm{mol} / \mathrm{L} \text { at Day } 8\end{array}$ & 1 & 112 \\
\hline $\begin{array}{l}\text { Urine output }<1 \mathrm{~L} \text { in } 24 \mathrm{~h} \text { and }<25 \% \text { fall in serum creatinine from } \\
\text { baseline in first } 24 \mathrm{~h} \text { post-transplant }\end{array}$ & 1 & 244 \\
\hline $\begin{array}{l}\text { Urine output }<75 \mathrm{~mL} / \mathrm{h} \text { in first } 48 \mathrm{~h} \text { or failure of serum } \mathrm{Cr} \text { to decrease } \\
\text { by } 10 \% \text { in the first } 48 \mathrm{~h}\end{array}$ & 1 & 66 \\
\hline $\begin{array}{l}\text { Need for dialysis in the first week after transplant or failure of serum } \\
\text { creatinine to decrease within } 24 \mathrm{~h} \text { after transplant }\end{array}$ & 1 & 104 \\
\hline
\end{tabular}

Table 4. Different DGF definitions. Taken from Yarlagadda et al., 2008 (with modifications).

In the same study, 10 proposal of diagnostic technique to identify DGF were also proposed (Figure 8). Starting from these grounds, we have stratified the early measures of graft function in three different categories: creatinine-based definition, urine-based definition and combined definition.

\subsection{Creatinine-based definition}

a. Serum creatinine level of $>3 \mathrm{mg} / \mathrm{dL}$ on the fifth day after surgery (Humar et al., 2000).

b. CCR2 and 24-h UC2

This score was created (Govani et al., 2002) combining the creatinine reduction ratio between days 1 and 2 (CRR2) and the 24-h urinary creatinine levels at post-KT day 2 (UC2)

Equation: $C R R 2(\%)=([C r 1-C r 2] \times 100) / C r 1) .(C r 1=$ serum creatinine level at post-KT day $1 ; C r 2=$ serum creatinine level at post-KT day 2). 
The cut-off value for poor function corresponded to a CCR $2 \leq 30 \%$.

c. CCR2

CCR2 was also adopted (Rodrigo et al., 2004; Salahudeen et al., 2004) as unique criterion for the definition of early graft function. The reported Authors used the same threshold value of $30 \%$.

d. CCR7

Creatinine reduction ratio at day 7 (CCR7) (Johnston et al., 2007) was proposed as score of initial graft function.

Equation: $C R R 7(\%)=([C r 0-C r 7] \times 100) / C r 0) .(C r 0=$ serum creatinine levels immediately before $\mathrm{KT}$ and no later than 6 hours after last dialysis; $\mathrm{Cr} 7=$ serum creatinine levels at post-KT day 7).

The cut-off value for poor function corresponded to a CCR7 $\leq 70 \%$ (Figure 9).

e. Number of days to achieve a creatinine clearance of $>10 \mathrm{~mL} / \mathrm{min}$, calculated by the Gault-Cockroft formula (Giral-Classe et al., 1998).

f. Serum creatinine level increased, remained unchanged or decreased by less than $10 \%$ per day immediately after surgery during three consecutive days for $>1$ week (Boom et al., 2000).
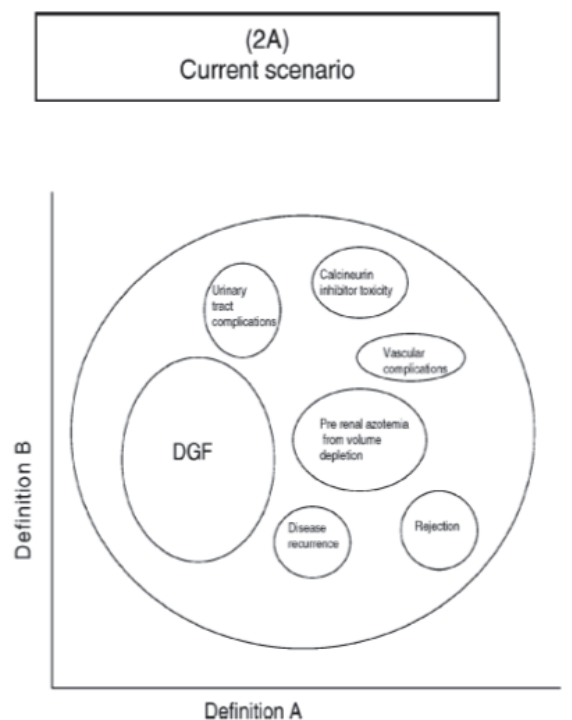

With the advent of a new diagnostic technique and/or improved definition (2B)

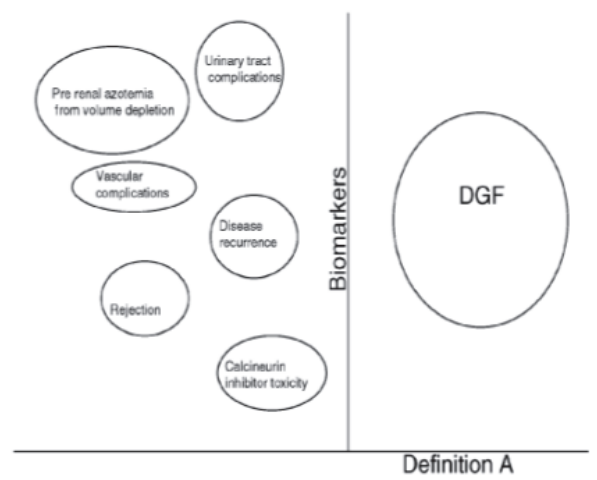

Fig. 8. Different clinical conditions that present as early graft dysfunction. (A) Current definitions do not allow us to distinguish DGF from other causes of graft dysfunction. (B) With an improved definition and/or diagnostic technique patients with DGF can be correctly classified. Taken from Yarlagadda et al., 2008. 

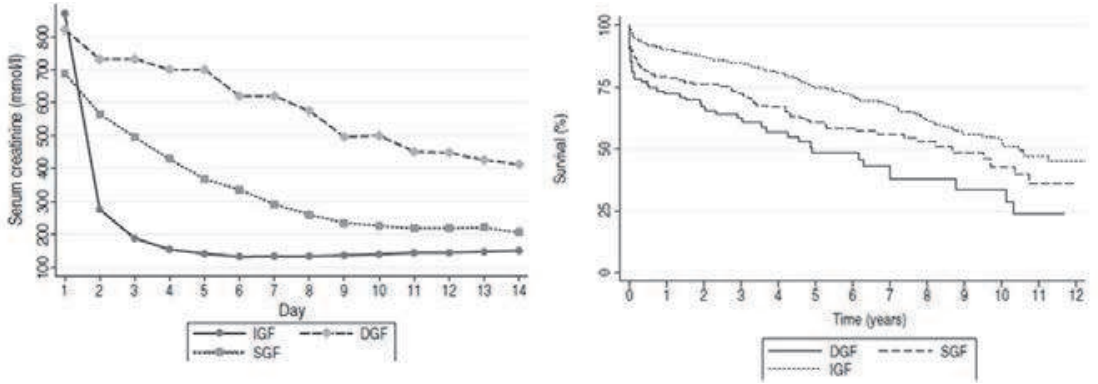

Fig. 9. Left: Decline in creatinine within 2 weeks post-KT. Right: graft survival curves. IGF: initial good function (CCR7 > 70\%), DGF: delayed graft function (need for dialysis), SGF: scarce graft function (CCR7 $\leq 70 \%$ no dialysis). Taken from Johnston et al., 2007.

\subsection{Urine-based definition}

UO7

Urine output at post-KT day 7 (UO7) was recently proposed (Lai et al., 2010).

Equation: UO7 = total urine output on day 7 post-transplantation $(\mathrm{mL}) /$ weight $(\mathrm{kg}) / 24$ hours.

UO7 presented an elevated power for the prediction of 1-year graft function: at ROC analysis, UO7 presented an elevated area under the curve (0.811) (Figure 10). A cut-off value of $500 \mathrm{~mL} / 24 \mathrm{~h}$ showed high sensitivity $(98.5 \%)$.

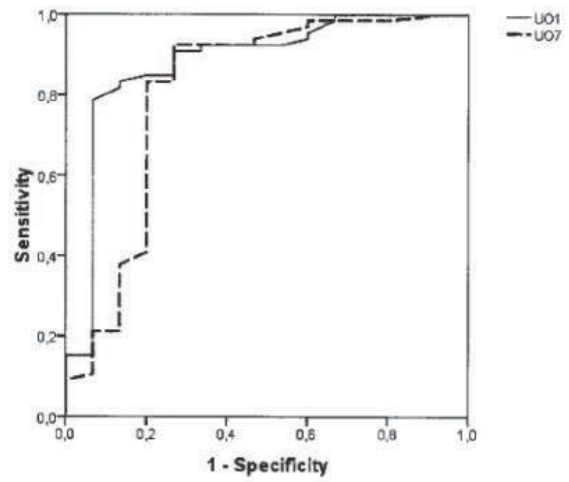

Fig. 10. ROC curves for post-KT day 1 urine output (UO1) and day 7 urine output (UO7) according to 1-year graft function (eGFR $\geq 30 \mathrm{~mL} / \mathrm{min} / 1.73 \mathrm{~m} 2)$. Taken from Lai Q et al, 2009.

\subsection{Combined definition}

\section{a. $\mathrm{Cr} 7$ and UO1}

A score based on the combination of serum creatinine at post-KT day 7 (Cr7) and urine output at post-KT day 1(UO1) was proposed (Schnuelle et al., 2007).

Equation: UO1 = total 1st postoperative day urine output $(\mathrm{mL}) /$ weight $(\mathrm{kg}) / 24$ hours. 
Kaplan-Maier survival estimates indicated a threshold effect of UO1 and Cr7, which could dissect the risk of graft failure. The thresholds referring to the 2nd quintile corresponded to a UO1 $>630 \mathrm{ml}$ and a Cr7 $<2.5 \mathrm{mg} / \mathrm{dl}$. Combination of both of the parameters predicted a 5year graft survival probability $>90 \%$, according to a hazard ratio of 0.21 (95\% CI $0.09-0.46$ ) (Figure 11).

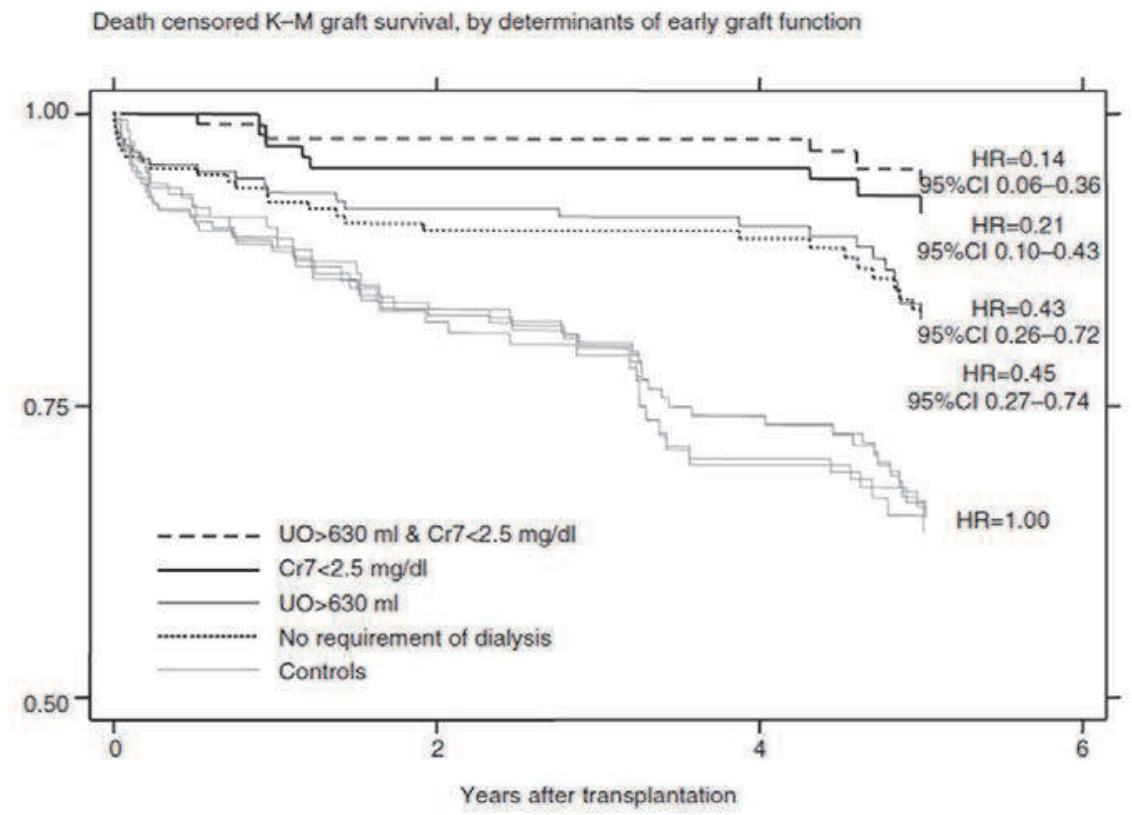

Fig. 11. Summary plot of 5-year graft survival estimates, by surrogates of early graft function as categorized by freedom from dialysis post-transplant, urine output exceeding $630 \mathrm{ml}$ post-transplant, decline of serum creatinine below $2.5 \mathrm{mg} / \mathrm{dl}$ during the 1st week, and the combination of the latter criteria. Survival curves of the respective controls not meeting these requirements are displayed in light-colored lines. Taken from Schnuelle et al., 2007.

b. A definition of DGF obtainable within 6 hours after KT was proposed (Gonwa et al., 2002). It was based on a rising serum creatinine level above that before surgery or a urine output of $<300 \mathrm{~mL}$ within $6 \mathrm{~h}$ of transplantation, despite diuretics and adequate volume. Adoption of a very early definition of no-graft function was adopted with the intent to choose the correct immunosuppressive therapeutic approach to the patients.

c. A new model for the definition of DGF was created (Halloran \& Hunsicker, 2001) by the combination of urine output of $<1 \mathrm{~L}$ in the first $24 \mathrm{~h}$ or a decrease in serum creatinine of $<20-30 \%$.

d. DGF was recently defined (Lai et al., 2009) as the presence of one of the following conditions: at least 1-day persistent oligoanuria $(\leq 500 \mathrm{~mL} / 24 \mathrm{~h})$ during the first week or an increased, unchanged, or decreased by $\leq 30 \%$ 7-day serum creatinine as compared with the pre-KT value. 


\section{Comparison among the scoring systems}

Many researches have been performed on the identification of pre- or early post-operative clinical predictors of graft function; however, the great majority of them were based on isolated studies, usually in the populations from which they were initially derived. Moreover, only a small number of papers have focalized on their attention on the comparison among the different scoring systems.

For example, a previously reported study (Schold et al., 2005) compared preoperative scores (ECD, DDS and DRS), showing DRS was the best model for the prediction of graft survival at multivariable analysis. In the same period, another study (Nyberg et al., 2005) showed the superiority of DDS respect to ECD.

The first comparative analysis of preoperative and early post-operative scores (Moore et al., 2007) tested the ability of these clinical variables to predict suboptimal early function variably assessed by: DGF (dialysis requirement during the first week), DGF duration, slow graft function (creatinine $>3 \mathrm{mg} / \mathrm{dl}$ on day 5) and creatinine reduction ratio on day 2 .

Multiple regression analysis was performed on 217 consecutive renal transplant recipients: DGF nomogram, DDS and ECD were compared. All scoring systems showed associations with early graft function, although only DGF nomogram remained statistically significant in the multiple regression model. However, the overall utility of the DGF nomogram in DGF prediction was moderate.

Two years later, a new comparative study (Moore et al., 2009) focalized on its attention on the role of pre- and post-KT models for the prediction of graft dysfunction: primary outcome measures were creatinine at 12 months and the development of chronic kidney disease stage $4 \mathrm{~T}$. The preoperative donor quality scores tested were: ECD, DDS, DRS and DGF nomogram: the postoperative early function measures were: dialysis requirement and duration; extended DGF according to Boom definition (Boom et al., 2000); Cr5, Cr7, CRR2, CRR7 and UO1.

Among the donor scoring systems, DRS was best associated with subsequent 6-month and 1-year allograft function. The study suggested a sort of "hierarchy": DRS > ECD > DDS > DGF nonogram.

These results could be explained by the different ways the scores were initially developed. For example, DGF nomogram was developed with regard to dialysis requiring DGF specifically, DDS was focalized on 6-month creatinine clearance, while DRS and ECD had graft failure as the end measure. The "granulated" complexity of DRS and DDS scores may explain their superiority above ECD.

Among the early function measures, extended definition of DGF, Cr5 and dialysis duration showed greatest predictive power in the patient population overall and in the subgroups of patients who not required or required dialysis, respectively. DGF resulted superior to the standard DGF definition: however, its importance lied in the simultaneous comparison of donor scores and early postoperative renal function to assess the best "baseline" indicator for later allograft dysfunction (Figure 12).

In another recent paper (Moore et al., 2010) dDGF (dialysis-based definition) and extDGF (extended; Boom et al., 2000) were compared (Figure 13). In the multivariable model, extDGF but not dDGF was significantly associated with graft failure (HR 1.47; p-value = 0.02). Similar results were observed for overall graft failure. The utility of extDGF as an early marker of late poor allograft outcomes suggested superiority over the traditional and often subjective dialysis-based definition. 

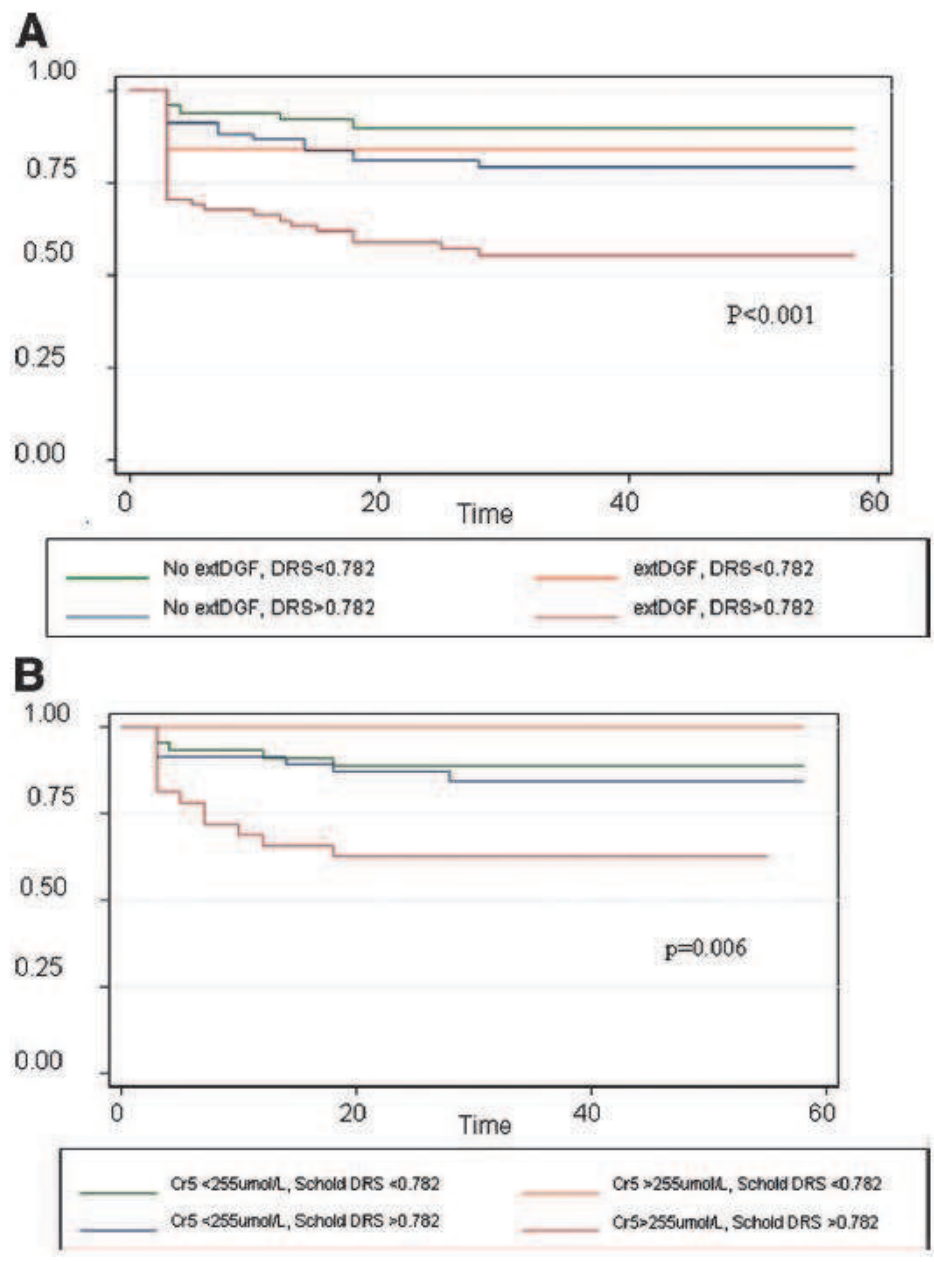

Fig. 12. (A) Kaplan-Meier survival curves for a combined variable of Donor Risk Score (DRS) and the extended definition of delayed graft function (extDGF) for time to stage 4T chronic kidney disease in all patients. (B) Kaplan-Meier survival curves for a combined variable of Donor Risk Score (DRS) and serum creatinine at day 5 (Cr5) for time to stage $4 \mathrm{~T}$ chronic kidney disease in patients not requiring dialysis immediately postoperatively. Taken from Moore et al., 2009. 


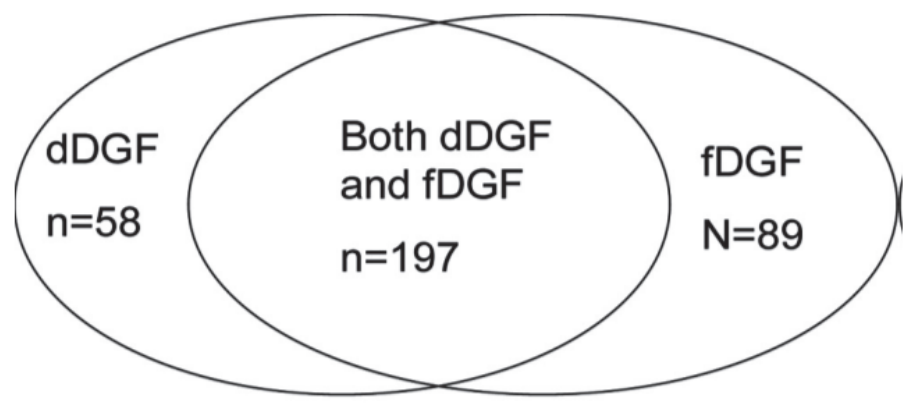

dDGF and fDGF absent: $n=406$

Fig. 13. Diagram shows distribution of early graft function. dDGF, dialysis-based definition of delayed graft function; fDGF (or extDGF), functional definition of delayed graft function. Taken from Moore et al., 2010.

Among creatinine-based models, Cr5 represented the "best" marker of early graft function in patients who didn't undergo a post-KT dialysis (Moore et al., 2009).

Indeed, the influence of pre- or post-KT dialysis on creatinine measurements independent of allograft excretory function was too great a confounder to allow meaningful interpretation of these parameters also in dialyzed patients.

Exclusive (Lai et al., 2010) or combined (Schnuelle et al., 2007) use of UO could be of some benefit in a better evaluation of these patients: however, more consistent large studies on this field are still required.

No comparative studies among clinical and histological scores have been reported. Studies are needed for a better understanding of the effective role of histological features and its comparison with pre- and immediately post-KT variables.

\section{Conclusion}

Donor scores, histological scores and early postoperative measures of renal allograft function may be of clinical utility in assessing the risk for subsequent renal dysfunction. This has relevance to organ allocation policy and also to the clinical management of individuals in the early postoperative period.

However, no one of the proposed criteria has still been internationally adopted.

Probably, a combined score based on pre- and post-operative clinical features and histological aspects may offer improved prognostication for graft outcome.

However, the first objective of a score must be its feasibility: its excessive "granulation" could transform it in a hardly adopted instrument in the care practice.

New studies focalized on the validation of previously proposed scores or for the development of new prognostication models are still required.

\section{Acknowledgment}

We thank the "Inter-University Consortium for Organ Transplantation".

We thank the "Kidney Transplant Group" of Sapienza University f Rome. 


\section{References}

Anglicheau, D.; Loupy, A.; Lefaucheur, C.; Pessione, F.; Létourneau, I. \& al. (2008). A simple clinico-histopathological composite scoring system is highly predictive of graft outcomes in marginal donors. American Journal of Transplantation, Vol.8, No.11, (November 2008), pp. 2325-2334.

Boom, H.; Mallat, MJ.; de Fijter, JW.; Zwinderman, AH. \& Paul, LC. (2000). Delayed graft function influences renal function, but not survival. Kidney International, Vol.58, No.2, (August 2000), pp. 859-866.

Daly, PJ.; Power, RE.; Healy, DA.; Hickey, DP.; Fitzpatrick JM. \& al. (2005). Delayed graft function: a dilemma in renal transplantation. British Journal of Urology International, Vol.96, No.4, (September 2005), pp. 498-501.

Giral-Classe, M.; Hourmant, M.; Cantarovich, D.; Dantal, J.; Blancho, G. \& al. (1998). Delayed graft function of more than six days strongly decreases long-term survival of transplanted kidneys. Kidney International, Vol.54, No.3, (September 1998), pp. 972-978.

Gonwa, TA.; Mai, ML.; Smith, LB.; Levy, MF.; Goldstein, RM. \& al. (2002). Immunosuppression for delayed or slow graft function in primary cadaveric renal transplantation. Use of low dose tacrolimus therapy with post-operative administration of anti-CD25 monoclonal antibody. Clinical Transplantation, Vol.16, No.2, (April 2002), pp. 144-149.

Govani, MV.; Kwon, O.; Batiuk, TD.; Milgrom, ML. \& Filo RS. (2002). Creatinine reduction ratio and 24-hour creatinine excretion on posttransplant day two. Simple and objective tools to define graft function. Journal of the American Society of Nephrology, Vol.13, No.2, (June 2002), pp. 1645-1649.

Halloran, PF. \& Hunsicker, LG. (2001) Delayed graft function. State of the art. Summit meeting, Scottsdale, Arizona, USA, November 10-11, 2000. American Journal of Transplantation, Vol.1, No.2, (July 2001), pp. 115-120.

Humar, A.; Payne, WD.; Sutherland, DE. \& Matas, AJ. (2000). Clinical determinants of multiple acute rejection episodes in kidney transplant recipients. Transplantation, Vol.69, No.11, (June 2000), pp. 2357-2360.

Irish, WD.; McCollum, DA.; Tesi, RJ.; Owen, AB.; Brennan, DC. \& al. (2003). Nomogram for predicting the likelihood of delayed graft function in adult cadaveric renal transplant recipients. Journal of the American Society of Nephrology, Vol.14, No.11, (November 2003), pp. 2967-2974.

Irish, WD.; Ilsley, JN.; Schnitzler, MA.; Feng, S. \& Brennan, DC. (2010). A risk prediction model for delayed graft function in the current era of deceased donor renal transplantation. American Journal of Transplantation, Vol.10, No.10, (October 2010), pp. 2279-2286.

Johnston, O.; O’Kelly, P.; Spencer, S.; Donohoe, J.; Walshe, JJ. \& al. (2006). Reduced graft function (with or without dialysis) vs immediate graft function - A comparison of longterm renal allograft survival. Nephrology Dialysis Transplantation, Vol.21, No.8, (August 2006), pp. 2270-2274.

Karpinski, J.; Lajoie, G.; Cattran, D.; Fenton, S.; Zaltzman, J. et al. (1999). Outcome of kidney transplantation from high-risk donors is determined by both structure and function. Transplantation, Vol.67, No.8, (April 1999), pp. 1162-1167. 
Lai, Q.; Pretagostini, R.; Poli, L.; Melandro, F.; Ferretti, S. et al. (2009). Delayed graft function decreases early and intermediate graft outcomes after expanded criteria donor kidney transplants. Transplantation Proceedings, Vol.41, No.4, (May 2009), pp. 11451148 .

Lai, Q.; Pretagostini, R.; Poli, L.; Levi Sandri, GB.; Melandro, F. et al. (2010). Early urine output predicts graft survival after kidney transplantation. Transplantation Proceedings, Vol.42, No.4, (May 2010), pp. 1090-1092.

Metzger, RA.; Delmonico, FL.; Feng, S.; Port, FK.; Wynn, JJ. \& al. (2003). Expanded criteria donors for kidney transplantation. American Journal of Transplantation, Vol.3, Suppl.4, (2003), pp. 114-125.

Moore, J.; Tan, K.; Cockwell, P.; Krishnan, H.; McPake, D. \& al. (2007). Predicting early renal allograft function using clinical variables. Nephrology Dialysis Transplantation, Vol.22, No.9, (September 2007), pp. 669-677.

Moore, J.; Ramakrishna, S.; Tan, K.; Cockwell, P.; Eardley, K. \& al. (2009). Identification of the optimal donor quality scoring system and measure of early renal function in kidney transplantation. Transplantation, Vol.87, No.4, (February 2009), pp. 578-586.

Moore, J.; Shabir, S.; Chand, S.; Bentall, A.; McClean, A. \& al. (2010). Assessing and comparing rival definitions of Delayed Renal Allograft Function for predicting subsequent graft failure. Transplantation, Vol.90, No.10, (September 2010), pp. 11131116.

Nyberg, SL.; Matas, AJ.; Rogers, M.; Harmsen, WS.; Velosa, JA. \& al. (2001). Donor scoring system for cadaveric renal transplantation. American Journal of Transplantation, Vol.1, No.2, (July 2001), pp. 162-170.

Nyberg, SL.; Matas, AJ.; Kremers, WK.; Thostenson, JD.; Larson, TS. \& al. (2003). Improved scoring system to assess adult donors for cadaver renal transplantation. American Journal of Transplantation, Vol.3, No.6, (June 2003), pp. 715-721.

Nyberg, SL.; Baskin-Bey, ES.; Kremers, W.; Prieto, M.; Henry, ML. \& al. (2005). Improving the prediction of donor kidney quality: deceased donor score and resistive indices. Transplantation, Vol.80, No.7, (October 2005), pp. 925-929.

Pessione, F.; Cohen, S.; Durand, D.; Hourmant, M.; Kessler, M. \& al. (2003). Multivariate analysis of donor risk factors for graft survival in kidney transplantation. Transplantation, Vol.75, No.3, (February 2003), pp. 361-367.

Pirani, CL. \& Salinas-Madrigal L. (1975). Evaluation of percutaneous renal biopsy.; In: Kidney pathology decentenial.; 1966-1975; SC. Sommers; Norwalk CT (Ed.); Appleton-Century-Crofts: 1975.

Pretagostini, R.; Lai, Q.; Poli, L.; Levi Sandri, GB.; Travaglia, D. \& al. (2009). Predictive characteristics of delayed graft function after expanded and standard criteria donor kidney transplantations. Transplantation Proceedings, Vol.41, No.4, (May 2009), pp. 1149-1151.

Rao, PS.; Schaubel, DE.; Guidinger, MK.; Andreoni, KA.; Wolfe, RA. \& al. (2009). A comprehensive risk quantification score for deceased donor kidneys: the kidney donor risk index. Transplantation, Vol.88, No.2, (July 2009), pp. 231-236.

Remuzzi, G.; Grinyò, J.; Ruggenenti, P.; Beatini, M.; Cole, EH. \& al. (1999). Early experience with dual kidney transplantation in adults using expanded donor criteria. Double Kidney Transplant Group (DKG). Journal of the American Society of Nephrology, Vol.10, No.12, (December 1999), pp. 2591-2598. 
Remuzzi, G.; Cravedi, P.; Perna, A.; Dimitrov, BD.; Turturro, M. \& al. (2006). Long-term outcome of renal transplantation from older donors. New England Journal of Medicine, Vol.354, No.4, (January 2006), pp. 343-352.

Rodrigo, E.; Ruiz, JC.; Piñera, C.; Fernández-Fresnedo, G.; Escallada, R. \& al. (2004). Creatinine reduction ratio on post-transplant day two as criterion in defining delayed graft function. American Journal of Transplantation, Vol.4, No.7, (July 2004), pp. 1163-1169.

Rosengard, BR.; Feng, S.; Alfrey, EJ.; Zaroff, JG.; Emond, JC. \& al. (2002). Report of the Crystal City meeting to maximize the use of organs recovered from the cadaver donor. American Journal of Transplantation, Vol.2, No.8, (September 2002), pp. 701711.

Salahudeen, AK.; Haider, N. \& May, W. (2004). Cold ischemia and the reduced long-term survival of cadaveric renal allografts. Kidney International, Vol.65, No.2, (February 2004), pp. 713-718.

Schnuelle, P.; Gottmann, U.; Köppel, H.; Brinkkoetter, PT.; Krzossok, S. \& al. (2007). Comparison of early renal function parameters for the prediction of 5-year graft survival after kidney transplantation. Nephrology Dialysis Transplantation, Vol.22, No.1, (January 2007), pp. 235-245.

Schold, JD.; Kaplan, B.; Baliga, RS. \& Meier-Kriesche, HU. (2005). The broad spectrum of quality in deceased donor kidneys. American Journal of Transplantation, Vol.5, No.4 Part.1, (April 2005), pp. 757-765.

Stratta, RJ.; Rohr, MS.; Sundberg, AK.; Armstrong, G.; Hairston, G. \& al. (2005). Increased kidney transplantation utilizing expanded criteria deceased organ donors with results comparable to standard criteria donor transplant. Annals of Surgery, Vol.239, No.5, (May 2004), pp. 688-695.

Yarlagadda, SG.; Coca, SG.; Garg, AX.; Doshi, M.; Poggio, E. \& al. (2008). Marked variation in the definition and diagnosis of delayed graft function: a systematic review. Nephrology Dialysis Transplantation, Vol.23, No.9, (September 2008), pp. 2995-3003. 


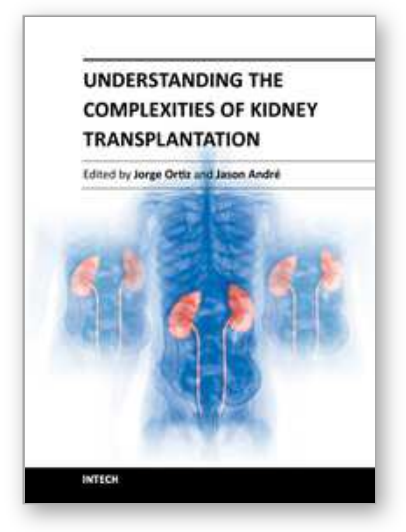

\author{
Understanding the Complexities of Kidney Transplantation \\ Edited by Prof. Jorge Ortiz
}

ISBN 978-953-307-819-9

Hard cover, 564 pages

Publisher InTech

Published online 06, September, 2011

Published in print edition September, 2011

Kidney transplantation is a complex field that incorporates several different specialties to manage the transplant patient. This book was created because of the importance of kidney transplantation. This volume focuses on the complexities of the transplant patient. In particular, there is a focus on the comorbidities and special considerations for a transplant patient and how they affect kidney transplant outcomes. Contributors to this book are from all over the world and are experts in their individual fields. They were all individually approached to add a chapter to this book and with their efforts this book was formed. Understanding the Complexities of Kidney Transplantation gives the reader an excellent foundation to build upon to truly understand kidney transplantation.

\title{
How to reference
}

In order to correctly reference this scholarly work, feel free to copy and paste the following:

Quirino Lai, Francesco Nudo, Vincenzo Morabito, Giovanni Battista Levi Sandri, Fabio Melandro, Lucia Parlati, Nicola Guglielmo, Marco Di Laudo, Manuela Garofalo, Luca Poli, Renzo Pretagostini and Pasquale B Berloco (2011). Donor Quality Scoring Systems and Early Renal Function Measurements in Kidney Transplantation, Understanding the Complexities of Kidney Transplantation, Prof. Jorge Ortiz (Ed.), ISBN: 978-953-307-819-9, InTech, Available from: http://www.intechopen.com/books/understanding-the-complexities-of-kidneytransplantation/donor-quality-scoring-systems-and-early-renal-function-measurements-in-kidneytransplantation

\section{INTECH}

open science | open minds

\section{InTech Europe}

University Campus STeP Ri

Slavka Krautzeka 83/A

51000 Rijeka, Croatia

Phone: +385 (51) 770447

Fax: +385 (51) 686166

www.intechopen.com

\section{InTech China}

Unit 405, Office Block, Hotel Equatorial Shanghai

No.65, Yan An Road (West), Shanghai, 200040, China

中国上海市延安西路65号上海国际贵都大饭店办公楼405单元

Phone: +86-21-62489820

Fax: $+86-21-62489821$ 
(C) 2011 The Author(s). Licensee IntechOpen. This chapter is distributed under the terms of the Creative Commons Attribution-NonCommercialShareAlike-3.0 License, which permits use, distribution and reproduction for non-commercial purposes, provided the original is properly cited and derivative works building on this content are distributed under the same license. 